\title{
ANALISIS DAYA TARIK WISATA RUMAH TRADISIONAL MASYARAKAT KAMPUNG LOLOAN, JEMBRANA-BALI
}

\author{
Dinar Sukma Pramesti \\ Email: dinar.pramesti@pib.ac.id \\ POLITEKNIK INTERNASIONAL BALI
}

\begin{abstract}
This research aimed at finding out the condition of tourist attraction of Loloan traditional houses from the internal and external aspects. This study is a descriptive qualitative study using a SWOT analysis. The informants were chosen based on purposive sampling. The results of the internal aspect analysis reveal that Loloan traditional houses are unique and have their own characteristics. Besides, other tourist attractions can support the attractiveness of Loloan traditional houses. They are Makam Keramat Buyut, a sacred cemetery, Baitul Qhadim Mosque, and Ijo Gading River. But, on another side, Loloan traditional houses also posses some weaknesses that need to be improved.

Their weaknesses are no an organization manage the tourist attraction as well as the facilities which are still considered lack. The results of external aspect analysis show that Loloan traditional houses bring the possibility for the local community to earn more income and to improve their economic state. It also can be a form of culture conservation. But it cannot be neglected that Loloan traditional houses will disappear one day as most of the local people started to build their houses in modern style. The competition with other tourist attractions can be considered as another threat to the existence of Loloan traditional houses
\end{abstract}

Keywords: SWOT Analysis, Traditional House, Loloan Community

\begin{abstract}
Abstrak
Penelitian ini bertujuan untuk mengetahui kondisi daya tarik wisata rumah tradisional masyarakat Kampung Loloan dilihat dari aspek internal dan eksternal. Penelitian ini merupakan penelitian deskriptif kualitatif dengan menggunakan analisis SWOT (strength, weakness, opportunity, threats). Informan dipilih dengan teknik purposive sampling. Hasil penelitian mengungkapkan bahwa dilihat dari aspek internal, daya tarik wisata rumah tradisional masyarakat Kampung Loloan memiliki kekuatan yaitu unik dan khas serta terdapat daya tarik wisata pendukung lain seperti Makam Keramat Buyut Lebai, Masjid Baitul Qhadim dan Sungai Ijo Gading.
\end{abstract}


Kelemahan yang dimiliki yaitu belum adanya kelompok atau organisasi pengelola pariwisata serta aktivitas dan fasilitas yang tersedia belum lengkap. Dilihat dari aspek eksternal, peluang yang ada yaitu dengan adanya pariwisata dapat menambah penghasilan yang dapat meningkatkan perekonomian masyarakat Kampung Loloan dan dapat digunakan sebagai wadah pelestarian budaya. Ancaman daya tarik wisata rumah tradisional masyarakat Loloan yaitu hilang dan berubahnya rumah tradisional masyarakat Kampung Loloan dan adanya persaingan dengan daya tarik wisata lain.

Kata Kunci: Analisis SWOT, Rumah Tradisional, Masyarakat Kampung Loloan

\section{Pendahuluan}

Kampung Loloan memiliki potensi budaya yang sangat kaya. Salah satu budaya Kampung Loloan yaitu rumah tradisional yang berbentuk rumah panggung. Rumah panggung masyarakat Kampung Loloan merupakan rumah peninggalan sejarah, seni dan budaya. Rumah tradisional masyarakat Kampung Loloan tidak memiliki Pura, seperti halnya kebanyakan rumah masyarakat tradisional Bali. Bali dikenal sebagai pulau yang dihuni oleh mayoritas umat Hindu, tetapi ternyata terdapat pula masyarakat Muslim yang telah berabad lamanya menghuni pulau Bali dan hidup berdampingan dengan masyarakat Hindu.

Masyarakat Muslim di Kampung Loloan membentuk citra lingkungan baru dengan mengangkat pola wujud rumah sesuai dengan asal tradisinya yaitu rumah panggung. Rumah panggung merupakan rumah yang tidak berdiri di atas tanah melainkan disokong atau didukung oleh sejumlah tiang-tiang vertikal. Rumah panggung dipilih selain karena asal tradisi, juga karena dapat beradaptasi dengan kondisi alam Loloan yang dekat dengan sungai Ijo Gading. Sungai Ijo Gading sering meluap dan mengakibatkan banjir.

Kekhasan budaya yang dimiliki rumah tradisional masyarakat kampung Loloan sebenarnya dapat menjadi daya tarik tersendiri untuk 
mampu mendatangkan wisatawan ke kampung Loloan. Sayangnya, daya tarik yang ada tersebut belum dimanfaatkan secara optimal. Ada banyak wisatawan yang datang ke kampung Loloan untuk melakukan ziarah makam yang terdapat di kampung Loloan. Kepala Bidang Pariwisata, Dinas Pariwisata dan Budaya Jembrana, Nyoman Wenten (Antara Bali, 2018), mengungkapkan wisatawan yang datang tersebut, seharusnya digiring untuk mengunjungi rumah tradisional kampung Loloan atau bahkan menginap di rumah tradisionalnya, disajikan suasana dan kebudayaan tradisional Loloan, termasuk menyuguhkan kuliner khas Kampung Loloan yang semuanya dikelola oleh masyarakat Kampung Loloan itu sendiri.

Berdasarkan uraian yang telah dipaparkan, dirasa perlu ada suatu penelitian yang bertujuan melihat daya tarik wisata rumah tradisional masyarakat kampung Loloan. Adapun permasalahan yang diangkat yaitu bagaimanakah daya tarik wisata rumah tradisional masyarakat Kampung Loloan dilihat dari aspek internal dan eksternal?

\section{Konsep Dan Teori}

Konsep dan teori yang dipilih untuk menjelaskan penelitian ini terangkum sebagai berikut.

\subsection{Daya Tarik Wisata}

Daya tarik wisata merupakan kata lain dari obyek wisata, namun sesuai peraturan pemerintah Indonesia tahun 2009, kata obyek wisata sudah tidak relevan lagi untuk menyebutkan suatu daerah tujuan wisatawan sehingga digunakanlah kata Daya Tarik Wisata. Berikut beberapa definisi mengenai daya tarik wisata menurut beberapa ahli. Ismayanti (2010: 147), mengungkapkan daya tarik wisata sebagai fokus utama penggerak pariwisata atau penggerak utama yang memotivasi wisatawan mengunjungi suatu tempat. Undang-undang Nomor 10 tahun 
2009 tentang kepariwisataan juga menyebutkan mengenai pengertian daya tarik wisata yaitu keanekaragaman kekayaan alam, budaya, dan hasil buatan manusia yang memiliki keunikan, keindahan, dan nilai yang menjadi sasaran atau tujuan kunjungan wisatawan.

Yoeti (2008: 164) mengungkapkan bahwa daya tarik wisata adalah segala sesuatu yang menarik wisatawan untuk mengunjungi suatu daerah tertentu. Pendit (2003: 35) juga mengungkapkan hal yang sama. Menurutnya daya tarik wisata adalah segala sesuatu yang menarik dan mempunyai nilai untuk dikunjungi dan dilihat. Spillane (1997: 43) menjabarkan daya tarik wisata dapat berupa flora dan fauna, bentang alam, hasil budidaya manusia seperti museum, monumen, candi, gedung bersejarah, musik tradisional, tarian dan adat istiadat.

Berdasarkan pengertian tersebut maka dapat disimpulkan bahwa daya tarik wisata merupakan faktor utama atau potensi yang menjadi pendorong kehadiran wisatawan ke suatu daerah tujuan wisata. Daya tarik wisata harus dirancang, dibangun dan dikelola secara profesional sehingga dapat menarik wisatawan untuk datang.

\subsection{Rumah Tradisional Masyarakat Kampung Loloan}

Rumah tradisional masyarakat Kampung Loloan berbentuk panggung. Menurut salah seorang tokoh Loloan, Haji Mussadad (Pramesti, 2014: 21), ciri rumah panggung Loloan yaitu tidak memiliki satu pun paku yang dipergunakan dalam konstruksi rumah panggung. Kayu yang digunakan yaitu jenis kayu tangi. Biasanya, sebagai sendi dipilih batu atau kayu tengulun. Sebuah rumah panggung biasanya mempergunakan 12, 16 atau 20 tiang. Ciri lain dari rumah panggung masyarakat Kampung Loloan ialah menggunakan genteng Palembang.

Rumah panggung Loloan tersusun atas tiga bagian yaitu lantai dasar/kolong, lantai tengah/induk dan lantai atas/loteng yang disebut para- 
para. Terdapat dua buah tangga untuk menghubungkan lantai bawah/kolong dengan lantai tengah atau induk. Tangga depan digunakan untuk tamu sedangkan tangga belakang digunakan untuk penghuni rumah atau kerabat dekat. Lantai bawah/kolong awalnya dibiarkan kosong. Hanya digunakan sebagai peninggian untuk mengantisipasi banjir. Semenjak dibangun permukiman di sekitar sungai Ijo Gading yaitu di wilayah Loloan, sungai Ijo Gading mengalami pelurusan dan tidak pernah dilanda banjir besar lagi. Masyarakat Loloan memanfaatkan lantai dasar/kolong sebagai tempat untuk menyimpan peralatan rumah tangga, peralatan bekerja, menyimpan kayu bakar dan bisa juga dimanfaatkan sebagai kandang ternak. Lantai dasar/kolong mempergunakan penutup gedek karena itulah, ruangan bisa multifungsi.

Lantai tengah/induk terbagi menjadi 3 bagian yaitu bagian depan, tengah dan belakang. Bagian depan terdapat ruangan yang disebut serambi/amben dan ruang depan. Di bagian tengah, terdapat bilik/kamar tidur. Di belakang, dimanfaatkan sebagai dapur. Lantai atas/loteng yang disebut para-para. Terdapat tangga untuk naik ke loteng/para-para (Pramesti, 2014: 21-22).

Pintu, jendela dan ventilasi rumah panggung di Loloan terbuat dari kayu tangi. Pintu, jendela dan ventilasi pada umumnya terdapat di bagian lantai tengah/induk. Pintu berbentuk persegi panjang. Jendela, rumah panggung Loloan bentuknya sama seperti pintu, tetapi ukurannya lebih kecil atau lebih rendah. Daun jendela terdiri atas 1 atau 2 daun jendela. Jendela dengan 1 daun disebut tongtongan. Tongtongan berasal dari bahasa Bugis yang berati jendela. Jendela dengan 2 daun disebut tingkapan yang berasal dari bahasa Melayu yang berati jendela. Pada bagian depan/ façade rumah panggung Loloan memiliki jumlah pintu dan jendela tiga buah. Ventilasi yang terdapat pada rumah panggung di Loloan yaitu ukiran, krepyak dan jaro (Pramesti, 2014: 69). 
Ragam hias yang digunakan pada rumah panggung di Loloan bersumber dari ajaran agama Islam. Ragam hias yang digunakan yaitu ragam hias timbul layar pada ujung atap, ragam hias tapak dare pada sisi ujung atap, ragam hias papan sisir berupa kayu-kayu yang dipasang bersusun pada atap. Pada dinding terdapat list kayu dan ukiran flora atau kaligrafi. Pada pintu dan jendela terdapat ragam hias gerbang berupa ukiran kayu yang diletakan di ambang pintu dan jendela (Pramesti, 2014: 70).

\subsection{Teori Daya Tarik Wisata}

Yoeti (2010: 34-35) menjelaskan bahwa suatu obyek wisata atau daya tarik wisata akan menarik untuk dikunjungi oleh wisatawan jika memenuhi tiga syarat, yaitu:

a. Something to see. Suatu daya tarik wisata harus mempunyai sesuatu yang bisa dilihat atau dijadikan tontonan oleh wisatawan. Dengan kata lain daya tarik wisata harus mempunyai hal khusus yang dapat menarik minat wisatawan untuk berkunjung.

b. Something to do. Wisatawan yang berkunjung harus bisa melakukan sesuatu yang berguna untuk memberikan perasaan senang, bahagia, relax melalui penyediaan fasilitas rekreasi seperti arena bermain, tempat makan terutama yang menyajikan makanan khas daerah setempat sehingga mampu membuat wisatawan lebih betah untuk tinggal

c. Something to buy. Wisatawan yang berkunjung harus bisa berbelanja barang yang menjadi ciri khas atau icon dari daerah tersebut, sehingga bisa dijadikan sebagai oleh-oleh.

Yoeti (2010: 181) juga menambahkan agar suatu daya tarik wisata dapat menarik, maka diperlukan juga kelengkapan dari sarana dan prasarana. Sarana kepariwisataan tersebut seperti: a) Perusahaan 
akomodasi yang meliputi hotel, losmen, bungalow; b) Perusahaan transportasi meliputi pengangkutan udara, laut atau kereta api dan bus-bus yang melayani khusus pariwisata saja; c) Rumah makan, restaurant, depot, warung; d) Toko-toko cinderamata khas dari obyek wisata tersebut yang notabene mendapat penghasilan hanya dari penjualan barang-barang cinderamata khas obyek tersebut.

Prasarana kepariwisataan yaitu semua fasilitas yang dapat memberikan pelayanan yang memuaskan kebutuhan wisatawan yang beraneka ragam (Yoeti, 2010: 183). Prasarana tersebut antara lain: a) Perhubungan: jalan raya, rel kereta api, pelabuhan udara dan laut, terminal; b) Instalasi pembangkit listrik dan instalasi air bersih; c) Sistem telekomunikasi, baik itu telepon, telegraf, radio, televisi, kantor pos; d) Pelayanan kesehatan baik itu puskesmas maupun rumah sakit; e) Pelayanan keamanan baik itu pos satpam penjaga obyek wisata maupun pos-pos polisi untuk menjaga keamanan di sekitar obyek wisata; f) Pelayanan wistawan baik itu berupa pusat informasi ataupun kantor pemandu wisata; g) Pom bensin.

Pengembangan sarana dan prasarana suatu daerah tujuan wisata harus dilakukan dengan sebaik mungkin. Apabila suatu daerah tujuan wisata dapat membuat wisatawan berkunjung dan betah untuk melakukan wisata disana, maka akan menyedot banyak pengunjung yang kelak akan berguna juga untuk peningkatan ekonomi baik di sekitar obyek wisata tersebut maupun pemerintah daerah.

\section{Metode Penelitian}

Penelitian ini merupakan penelitian deskriptif kualitatif dengan menggunakan analisis SWOT (strength, weakness, opportunity, threats). Menurut Sugiyono (2014: 21) metode deskriptif digunakan untuk menggambarkan atau menganalisis hasil penelitian tetapi tidak digunakan 
untuk membuat kesimpulan yang lebih luas. Informan pada penelitian ini dipilih melalui teknik purposive sampling yaitu secara sengaja berdasarkan kriteria yang telah ditentukan dan ditetapkan berdasarkan tujuan penelitian. Adapun kriteria informan yang ditunjuk atau dipilih dalam penelitian ini adalah informan yang mengetahui kondisi Kampung Loloan dan rumah tradisional masyarakatnya. Metode pengumpulan data yang digunakan pada penelitian ini adalah observasi, wawancara dan studi dokumentasi.

\section{Daya Tarik Wisata Rumah Tradisional Masyarakat Kampung Loloan}

Berikut uraian daya tarik wisata rumah tradisional masyarakat Kampung Loloan dilihat dari dua aspek yaitu internal dan eksternal.

\subsection{Aspek Internal Daya Tarik Wisata Rumah Tradisional Masyarakat Kampung Loloan}

Aspek internal adalah aspek yang terdiri dari variabel yang ada di dalam lingkungan objek penelitian. Dalam aspek internal terdapat kekuatan dan kelemahan yang berpengaruh dalam kegiatan operasional daya tarik wisata rumah tradisional masyarakat Kampung Loloan. Berdasarkan hasil observasi dan wawancara langsung, aspek internal dapat dipaparkan sebagai berikut:

a. Kekuatan Daya Tarik Wisata Rumah Tradisional Masyarakat Kampung Loloan

Berdasarkan hasil observasi dan wawancara langsung diperoleh beberapa kekuatan yang dimiliki daya tarik wisata rumah tradisional masyarakat Kampung Loloan, yaitu sebagai berikut:

1) Rumah Tradisional Masyarakat Kampung Loloan Unik dan Khas

Rumah tradisional masyarakat Loloan unik dan khas karena berbeda dengan rumah tradisional masyarakat Bali pada umumnya. Rumah tradisional masyarakat Kampung Loloan 
berbentuk rumah panggung. Bentuk rumah panggung ini dipilih karena merupakan budaya khas yang dibawa oleh masyarakat Bugis dan Melayu yang datang dan menetap di wilayah Jembrana pada masa kerajaan Jembrana. Bentuk rumah panggung juga dipilih sebagai adaptasi dari lingkungan Kampung Loloan yang rawan banjir. Uniknya rumah tradisional masyarakat Kampung Loloan, menyebabkan wisatawan tertarik mengunjungi Kampung Loloan. Biasanya wisatawan yang datang merupakan kaum akademisi seperti dosen dan mahasiswa dari berbagai Perguruan Tinggi di Indonesia maupun di luar negeri.

2) Kampung Loloan Memiliki Daya Tarik Wisata Pendukung selain Rumah Tradisional Masyarakatnya.

Kampung Loloan selain memiliki rumah tradisional yang dapat dijadikan daya tarik wisata, juga memiliki daya tarik wisata lain berupa peninggalan sejarah diantaranya makam Buyut Lebai dan Masjid Baitul Qhadim. Keduanya merupakan peninggalan sejarah yang sering didatangi wisatawan. Kampung Loloan juga memiliki daya tarik wisata pendukung yang diberdayakan oleh masyarakatnya yaitu rumah baca Loloan dan tepian sungai Ijo Gading. Daya tarik wisata ini dibangun secara mandiri oleh masyarakat Kampung Loloan.

b. Kelemahan Daya Tarik Wisata Rumah Tradisional Masyarakat Kampung Loloan

Berdasarkan hasil observasi dan wawancara langsung diperoleh beberapa kelemahan yang dimiliki daya tarik wisata rumah tradisional masyarakat Kampung Loloan, yaitu sebagai berikut:

1) Belum Ada Kelompok atau Organisasi Pengelola Pariwisata

Ditetapkannya daya tarik wisata rumah tradisional masyarakat Kampung Loloan sebagai salah satu daya tarik wisata 
di Kabupaten Jembrana, tidak diikuti dengan pembentukan kelompok atau organisasi pengelola pariwisata. Saat ini pengelolaan daya tarik wisata rumah tradisional masyarakat Kampung Loloan hanya dilakukan secara mandiri oleh masyarakat setempat. Dari pengamatan yang peneliti lakukan, terlihat masyarakat kurang terampil dalam mengelola. Hal ini tampak jelas dengan tidak terdatanya jumlah wisatawan yang datang, minimnya kegiatan yang dapat dilakukan wisatawan, minimnya fasilitas penunjang pariwisata, dan promosi yang belum efektif. Wisatawan yang datang ke Kampung Loloan biasanya hanya menghabiskan waktu yang relatif singkat dan mengakibatkan kurangnya keinginan wisatawan untuk melakukan kunjungan ulang dalam waktu yang singkat. Pengelola juga memiliki peran dalam promosi. Dengan tidak adanya pengelola pariwisata Kampung Loloan maka, saat ini promosi dilakukan seadanya. Promosi hanya dilakukan secara mandiri oleh masyarakat Kampung Loloan melalui media online.

2) Terbatasnya Kegiatan Wisatawan dan Minimnya Fasilitas

Daya tarik wisata rumah tradisional masyarakat Kampung Loloan belum berkembang dengan optimal karena belum banyak kegiatan yang dapat wisatawan lakukan dan masih minim fasilitas. Sejauh ini di Kampung Loloan wisatawan hanya terpenuhi aspek something to see dan something to do saja. Wisatawan dapat mengamati keunikan rumah tradisional masyarakat Kampung Loloan saja. Jika ingin menyaksikan kesenian tradisional masyarakat Loloan, wisatawan harus menyesuaikan waktu kunjungan dengan waktu diselenggarakannya festival budaya atau acara-acara lainnya karena hanya pada saat itu saja kesenian tradisional masyarakat Loloan ditampilkan. 
Aspek something to do belum berkembang dengan optimal, karena wisatawan hanya dapat duduk dan berbincang dengan pemilik rumah maupun warga setempat. Aspek something to buy merupakan aspek yang sama sekali belum ada di Kampung Loloan. Masyarakat di Kampung Loloan belum memanfaatkan kedatangan wisatawan untuk mendapatkan tambahan penghasilan misalnya dari penjualan tiket masuk, penjualan cinderamata ataupun makanan khas Loloan.

Selain minim kegiatan, Kampung Loloan juga masih minim fasilitas. Beberapa fasilitas yang dimiliki Kampung Loloan yaitu tempat ibadah, tempat aktivitas outdoor, warung makan, akses jalan, tempat parkir, area pejalan kaki, puskesmas, tempat sampah, jaringan telekomunikasi, air bersih dan jaringan listrik. Sarana ibadah untuk wisatawan tersedia bagi wisatawan Muslim yaitu Masjid Baitul Qhadim. Tempat untuk duduk menikmati keindahan alam tersedia di tepian sungai Ijo Gading. Warung makan juga telah tersedia bagi wisatawan yang datang ingin berbelanja makanan. Akses jalan menuju Kampung Loloan dapat dilalui kendaraan roda dua maupun roda empat karena jalan yang ada cukup besar dan kondisi jalan pun baik dan sudah di aspal. Di Kampung Loloan juga telah tersedia tempat parkir yang luas untuk kendaraan roda empat maupun bus pariwisata. Tersedia fasilitas pejalan kaki berupa trotoar yang memadai. Puskesmas, tempat sampah, jaringan telekomunikasi, air bersih, jaringan listrik juga telah tersedia di Kampung Loloan.

Sayangnya fasilitas penginapan untuk tempat tinggal bagi wisatawan yang datang, belum tersedia. Tidak adanya hotel atau penginapan membuat pengunjung tidak bisa menghabiskan waktunya lebih dari 24 jam di lokasi daya tarik wisata ini. 
Walaupun tidak dibangun hotel yang mewah, rumah-rumah penduduk sebenarnya bisa dijadikan penginapan untuk pengunjung, tapi belum ada masyarakat yang melakukan hal tersebut. Hal ini disebabkan masyarakat kurang paham dalam memanfaatkan peluang di bidang bisnis penginapan. Kondisi rumah juga menjadi suatu kendala. Tidak semua rumah panggung bisa dijadikan tempat menginap bagi wisatawan. Rumah tradisional masyarakat Kampung Loloan banyak yang kurang mendapat perhatian dari pemiliknya. Banyak rumah panggung yang telah usang bahkan reot karena dimakan usia. Fasilitas berbelanja oleh-oleh khas Loloan, toilet umum, pos pemandu wisata, pos keamanan, ATM dan Pom Bensin juga belum tersedia.

\subsection{Aspek Eksternal Daya Tarik Wisata Rumah Tradisional Masyarakat Kampung Loloan}

Aspek eksternal adalah aspek yang terdiri dari variabel yang ada di luar lingkungan objek penelitian. Di dalam aspek eksternal terdapat peluang dan ancaman/tantangan yang akan dihadapi dan memengaruhi kegiatan operasional tempat objek penelitian rumah tradisional masyarakat Kampung Loloan. Berdasarkan hasil observasi dan wawancara langsung dapat dipaparkan sebagai berikut:

a. Peluang Daya Tarik Wisata Rumah Tradisional Masyarakat Kampung Loloan

Berdasarkan hasil observasi dan wawancara langsung diperoleh beberapa peluang yang dimiliki daya tarik wisata rumah tradisional masyarakat Kampung Loloan, yaitu sebagai berikut:

1) Dapat Meningkatkan Perekonomian dan Memberdayakan Masyarakat Kampung Loloan 
Dari sudut ekonomi, kegiatan pariwisata dapat memberikan sumbangan terhadap penerimaan daerah bersumber dari pajak, retribusi parkir dan karcis atau dapat mendatangkan devisa dari para wisatawan mancanegara yang berkunjung. Adanya pariwisata juga akan menumbuhkan usaha-usaha ekonomi yang saling merangkai dan menunjang kegiatannya sehingga dapat meningkatkan pendapatan masyarakat. Pariwisata dapat pula digunakan sebagai sarana untuk menyerap tenaga kerja sehingga dapat mengurangi angka pengangguran dan meningkatkan angka kesempatan kerja. Mempertimbangkan hal tersebut, maka penanganan yang baik sangat diperlukan dalam upaya pengembangan daya tarik wisata rumah tradisional masyarakat Kampung Loloan.

2) Dapat Menjadi Wadah untuk Melestarikan Kebudayaan Loloan.

Masyarakat Kampung Loloan memiliki kekhawatiran terhadap kelestarian budayanya termasuk rumah tradisional masyarakatnya. Dengan adanya pariwisata di Kampung Loloan diharapkan nantinya masyarakat Kampung Loloan ingin tetap melestarikan budayanya dan mempertahankan keberadaan rumah tradisionalnya, apalagi rumah tradisional tersebut mampu menambah penghasilan bagi masyarakat Kampung Loloan. Salah satu upaya yang telah dilakukan untuk melestarikan budaya yaitu dengan menggelar festival Budaya Loloan. Festival budaya Loloan digelar agar masyarakat dan generasi muda mengenal budaya Kampung Loloan. Festival ini diadakan oleh remaja Kampung Loloan dengan biaya yang bersumber dari sumbangan masyarakat. Harapan masyarakat ke depannya festival ini juga mampu menarik wisatawan untuk datang ke Kampung Loloan, 
sehingga festival ini akan rutin digelar dan budaya Kampung Loloan tetap terjaga.

b. Ancaman Daya Tarik Wisata Rumah Tradisional Masyarakat Kampung Loloan

Berdasarkan hasil observasi dan wawancara langsung diperoleh beberapa ancaman yang dimiliki daya tarik wisata rumah tradisional masyarakat Kampung Loloan, yaitu sebagai berikut:

1) Hilang dan Berubahnya Rumah Tradisional Masyarakat Kampung Loloan

Dulu semua rumah yang ada di Kampung Loloan berbentuk rumah panggung. Sayangnya saat ini, rumah panggung tersebut sudah tergeser oleh munculnya bangunan megah dan bertingkat. Saat ini jumlah rumah panggung masyarakat Kampung Loloan hanya tinggal 80 buah. Hilangnya rumah panggung masyarakat Kampung Loloan tersebut disebabkan karena masyarakat menjual rumah panggung miliknya kepada kolektor bangunan antik dan kemudian membangun rumah dengan arsitektur modern. Selain ancaman hilangnya rumah panggung, Kampung Loloan juga dihadapkan dengan ancaman berubahnya bentuk rumah panggung. Rumah panggung yang ada saat ini sudah diubah bentuknya dan disesuaikan dengan kebutuhan saat ini. Kebanyakan yang mengalami perubahan adalah bagian kolong rumah panggung. Bagian kolong rumah panggung yang awalnya terbuka, kini ditutup oleh dinding beton. Hal ini disebabkan karena bertambahnya jumlah penghuni rumah yang menuntut tersedianya kamar yang lebih banyak. Bagian kolong yang ditutup dinding beton tersebut digunakan sebagai kamar tambahan. Ada juga yang menutup bagian kolong dan menggunakannya sebagai warung. 
2) Adanya Persaingan dengan Daya Tarik Wisata Lain

Banyaknya pesaing-pesaing pariwisata dengan fasilitas yang baik tentu menjadi ancaman berarti bagi daya tarik wisata rumah tradisional masyarakat Kampung Loloan untuk dapat bersaing dengan daya tarik wisata lain di Kabupaten Jembrana atau di daerah-daerah lain. Saingan daya tarik wisata rumah tradisional masyarakat Kampung Loloan yang terdekat yaitu daya tarik wisata Perancak. Daya tarik wisata ini populer sebagai kampung nelayan, tampilan pantainya cukup unik dipenuhi dengan jejeran perahu nelayan yang berwarna-warni. Kampung nelayan di Negara ini diminati terutama oleh wisatwan muda yang suka foto selfie atau hunting photo-photo cantik dan instagramable. Saingan terberat di daerah lain yaitu daya Tarik wisata Desa Penglipuran di Kabupaten Bangli. Daya Tarik wisata ini sama-sama menampilkan rumah tradisional masyarakatnya. Daya Tarik wisata Penglipuran sudah lebih tertata dan sudah menambah penghasilan bagi masyarakatnya dibanding daya tarik wisata rumah tradisional masyarakat Kampung Loloan.

\section{Penutup}

Analisis internal terhadap daya tarik wisata rumah tradisional masyarakat Kampung Loloan, ditemukan bahwa daya tarik wisata rumah tradisional masyarakat Kampung Loloan memiliki kekuatan dilihat dari indikator daya tarik wisata yang unik dan khas karena berada di Pulau Bali yang mayoritas penduduknya beragama Hindu, sedangkan rumah tradisional masyarakat Kampung Loloan kental dengan nuansa Islam dan kebudayaan Melayu. Daya tarik wisata rumah tradisional masyarakat Kampung Loloan juga memiliki daya tarik wisata pendukung lain seperti Makam Keramat Buyut Lebai, Masjid Baitul Qhadim dan Sungai Ijo 
Gading. Ketiga daya Tarik wisata ini merupakan kekuatan karena dapat menjadi alternatif maupun pendukung kegiatan bagi wisatwan yang datang ke daya tarik wisata rumah tradisional masyarakat Kampung Loloan.

Kelemahan yang dimiliki daya tarik wisata rumah tradisional masyarakat Kampung Loloan yaitu belum adanya kelompok atau organisasi pengelola pariwisata. Hal ini menyebabkan daya tarik wisata rumah tradisional masyarakat Kampung Loloan belum tertata dengan baik dan masih kurang dari segi promosi. Dilihat dari aktivtas dan fasilitas juga belum lengkap yakni belum adanya toko yang menjual cinderamata, penginapan, toilet umum, pos pemandu wisata, pos keamanan, ATM dan pom bensin.

Analisis eksternal mengidentifikasi faktor eksternal yang merupakan peluang dan ancaman daya tarik wisata rumah tradisional masyarakat Kampung Loloan. Peluang daya tarik wisata rumah tradisional masyarakat Kampung Loloan yaitu dengan adanya pariwisata dapat menambah penghasilan yang dapat meningkatkan perekonomian masyarakat Kampung Loloan. Adanya pariwisata akan menumbuhkan usaha-usaha ekonomi yang saling merangkai dan menunjang kegiatannya sehingga dapat meningkatkan pendapatan masyarakat. Pariwisata dapat pula digunakan sebagai sarana untuk menyerap tenaga kerja sehingga dapat mengurangi angka pengangguran dan meningkatkan angka kesempatan kerja. Peluang lainnya yaitu dapat digunakan sebagai wadah pelestarian budaya. Masyarakat Kampung Loloan memiliki kekhawatiran terhadap kelestarian budaya termasuk rumah tradisional masyarakatnya. Dengan adanya pariwisata di Kampung Loloan diharapkan nantinya masyarakat Kampung Loloan ingin tetap melestarikan budaya dan mempertahankan keberadaan rumah tradisionalnya.

Ancaman daya tarik wisata rumah tradisional masyarakat Loloan yaitu hilang dan berubahnya rumah tradisional masyarakat Kampung 
Loloan akibat tergerus perkembangan zaman dan adanya persaingan dengan daya tarik wisata lain yang berada di kabupaten Jembrana maupun di daerah-daerah lainnya di Bali.

Berdasarkan simpulan yang telah disampaikan, maka dapat diajukan rekomendasi yaitu masyarakat kampung Loloan dapat melakukan pengembangan daya tarik wisata sesuai dengan analisis kekuatan, kelemahan, ancaman dan peluang yang ada. Kekuatan dan peluang yang ada pada daya tarik wisata rumah tradisional masyarakat kampung Loloan harus dapat dikenali dan dilakukan refleksi sebagai langkah awal atau tonggak pengembangan agar mampu meningkatkan jumlah wisatawan yang datang dan meningkatkan kenyamanan wisatawan yang datang ke daya tarik wisata rumah tradisional masyarakat kampung Loloan. Kelemahan dan ancaman yang dimiliki daya tarik wisata rumah tradisional masyarakat Kampung Loloan harus ditanggulangi agar tidak menjadi sebuah penghalang atau penghambat bagi pengembangan daya tarik wisata rumah tradisional masyarakat kampung Loloan.

\section{Daftar Pustaka}

Ismayanti. 2010. Pengantar Pariwisata. Jakarta: PT Gramedia Widisarana Indonesia

Pendit, Nyoman S. 2003. Ilmu Pariwisata Sebuah Pengantar Perdana. Jakarta: pradnya paramita

Pramesti, Dinar Sukma. 2014. Sistem Spasial dan Tipologi Rumah Panggung di Desa Loloan, Jembrana (Bali). E-Jurnal: Ruang-Space (Jurnal Lingkungan Binaan). Vol. 1 No.1 April 2014. Hal 67-84

Spillane, James J.1997. Pariwisata Indonesia. Kanisiua. Yogyakarta

Sugiyono. 2014. Metode Penelitian Pendidikan Pendekatan Kuantitatif, Kualitatif Dan R\&D. Bandung: Alfabeta

Yoeti. Oka A. 2008. Perencanaan dan Pengembangan Pariwisata. Jakarta. PT. Pradnya Paramita

2010. Dasar-Dasar Pengertian Hospitality dan Pariwisata. Bandung: PT. Alumni

\section{Undang-Undang:}

Undang-Undang Republik Indonesia Nomor 10. Tahun 2009 tentang Kepariwisataan 


\section{Internet:}

Antara Bali. 18 September, 2018. Masyarakat Melayu Jembrana Sikapi Globalisasi Dengan Ikhtiar Budaya. https://bali.antaranews. com/berita/132002/masyarakat-melayu-jembrana-sikapiglobalisasidengan-ikhtiar-budaya. Diakses 1 Januari 2019

\section{Profil Penulis}

Dinar Sukma Pramesti, S.T., M.T. lahir di Denpasar 12 September 1988. Menamatkan Sarjana Teknik Arsitektur di Universitas Udayana pada tahun 2010. Melanjutkan Pendidikan Magister di bidang arsitektur dengan mengambil konsentrasi Arsitektur Kajian Lingkungan Binaan Etnik di Pascasarjana Universitas Udayana yang diselesaikan tahun 2013. Memiliki pengalaman sebagai arsitek di sebuah perusahaan arsitek, kontraktor, konsultan dan design planning di Denpasar serta menjadi asisten peneliti, editor buku dan penelitian di bidang arsitektur dan pariwisata. Pengalamannya ini membawanya menjadi Dosen D4 Manajemen Perhotelan di Politeknik Internasional Bali. 